But how to bring all this about? Normally, such tragedies are reported in the press, and a letter to the editor of various influential newspapers serves to call attention to the issues and may help. This is, of course, not enough. In this instance, there was no news coverage, and we were reluctant to contact the family to obtain more details about the driver, the primary cause of this tragedy. They were, no doubt, overwhelmed with guilt-some justified, per- haps - for the poor judgment shown in allowing a 6 year old to skate-board and to do so without a helmet. But, in fairness to the family, we, society, failed to make the need for these safety measures widely evident. And in particular, we failed to remove the dangerous driver from circulation. Furthermore, there is little likelihood that their guilt would have been assuaged by the police report; it is almost certain to have, in effect, 'blamed the victim' or his parents.

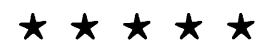

\title{
New features in the journal
}

In this issue we introduce two new features, one of which was previewed in an earlier issue. This is the Introduction to Statistics column written by Robert Platt in which he attempts to simplify points that, for many of us, including those who fancy themselves well trained researchers, often stumble over. But his main audience is intended to be nonresearch readers whose eyes glaze over when they read the words 'confidence interval' or 'analysis of variance'. Platt will do his best to keep it simple without compromising the accuracy of what is written. This, like so much else the balancing act this journal attempts, will be difficult. Please let him and me know how he is succeeding, and, if you have any favourite statistical mysteries that need to be unravelled, don't hesitate to ask.

The other new feature is an occasional column from a frequent contributor to PedNet (Pedestrian Network), one of the many listservers available through e-mail that include topics related to injury prevention. The writer, Peter Jacobsen, is an engineer in California. His comments attracted my attention and I asked him to highlight any 'threads' he believes will be of interest to our readers.

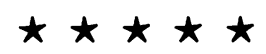

\section{Medical Editors Trial Amnesty}

META (Medical Editors Trial Amnesty) was initiated by the indomitable Ian Roberts, a hardworking member of our editorial board. It arises from his concern - a concern shared by many others - that there is a bias by editors, and perhaps by reviewers, against publishing trials with negative results. Thus, when attempts are made to systematically review the literature, especially using meta-analysis, these results are not available and the conclusions likely to be distorted. We have agreed, along with many other journals, to publish the appeal to researchers who have such unpublished trials, to submit the details (see p 233). I urge everyone to do so.

I B PLESS Editor 